\title{
Urethral plasticity and quality of life associated with the surgical technique in Unidad Médica de Alta Especialidad Mérida
}

\section{Plastia uretral y calidad de vida asociada a la técnica quirúrgica en la Unidad Médica de Alta Especialidad Mérida}

\author{
Edgar Surur-Zaibaka, Patricia B. Bolado-García*, Gonzalo J. Gamboa-López, Tania Gómez-Ávalos and \\ Luis F. Mena-Ramírez \\ High Specialty Medical Unit, Centro Médico Nacional Ignacio García Téllez, IMSS, Mérida, Yucatán, Mexico
}

\begin{abstract}
Objective: To determine the quality of life associated with the surgical technique in postoperative patients with urethral plasty. Methods: 29 patients operated between January-2011 and December-2015 were studied. The questionnaires Euroqol 5-D and International Prostate Symptom Score were applied to measure quality of life and detect relapses, respectively. Descriptive statistics were performed, cumulative incidence, relative risk and attributable fraction were calculated. Results: the incidence of relapse detected by the International Prostate Symptom Score was 69\% ( $p=0.011)$; the relative risk was 2.19 (95\% confidence interval: 2.092-2.288). The fraction attributable to the exposure was $54 \%$. The quality of life was associated with the length of the lesion $(p=0.046)$, low urinary symptoms $(p=0.004)$ and the individual perception of the state of health $(p=0.003)$. The location of the lesion was associated with relapse $(p=0.008)$. Quality of life was not associated with type of plasty $(p>0.05)$. Conclusions: The incidence of postoperative recurrence is high. The quality of life is independent of the surgical technique, but it is associated with the length of the lesion and urinary symptoms.
\end{abstract}

KEY WORDS: Urethral plasty. Quality of life. International Prostate Symptom Score. Euroqol 5-D. Relapse.

\section{Resumen}

Objetivo: Determinar la calidad de vida asociada con la técnica quirúrgica en pacientes posoperados de plastia uretral. Método: Se estudiaron 29 pacientes intervenidos entre enero de 2011 y diciembre de 2015. Se aplicaron los cuestionarios Eurogol 5-D e International Prostate Symptom Score para medir calidad de vida y detectar recaídas, respectivamente. Se realizó estadística descriptiva, y se calcularon la incidencia acumulada, el riesgo relativo y la fracción atribuible. Resultados: $L a$ incidencia de recaídas detectada por el International Prostate Symptom Score fue del 69\% $(p=0.011)$; el riesgo relativo fue de 2.19 (intervalo de confianza del 95\%: 2.092-2.288). La fracción atribuible a la exposición fue del 54\%. La calidad de vida se asoció con la longitud de la lesión $(p=0.046)$, los síntomas urinarios bajos $(p=0.004)$ y la percepción individual del estado de salud $(p=0.003)$. La localización de la lesión se asoció con recaída $(p=0.008)$. La calidad de vida no se asoció con el tipo de plastia $(p>0.05)$. Conclusiones: La incidencia de recurrencia posquirúrgica es alta. La calidad de vida es independiente de la técnica quirúrgica, pero está asociada con la longitud de la lesión y con los síntomas urinarios.

PALABRAS CLAVE: Plastia uretral. Calidad de vida. International Prostate Symptom Score. Euroqol 5-D. Recaída.

\author{
Correspondence: \\ *Patricia Berenice Bolado-García \\ CMD Calle 30x39 \#439 Col. Industrial, \\ Ex-terrenos El Fénix \\ C.P. 97150, Mérida, Yucatán, México \\ E-mail: investigacion.umae.imss@gmail.com; \\ patricia.bolado@imss.gob.mx
}

Date of reception: 29-01-2018

Date of acceptance: 11-05-2018

DOI: $10.24875 / C I R U E . M 18000046$
Cir Cir. 2018;86:273-280

Contents available at PubMed www.cirugiaycirujanos.com 


\section{Introduction}

"Urethral stricture" is the preferred term to describe an abnormal narrowing of any segment of the urethra surrounded by the corpus spongiosum, and specifically involves varying degrees of spongiofibrosis ${ }^{1}$. It is a relatively common condition in men, with a frequency of $229-627 / 100,000$ men, and $0.6 \%$ of the population is at risk, usually older men².

Urethral stricture is associated with signs and symptoms of urinary obstruction. Its etiology can be classified as iatrogenic, traumatic, inflammatory and idiopathic'. Plasty is a therapeutic option, the purpose of which is a lasting and functional reconstruction. Recurrence varies depending on the cause of the lesion, on prognostic factors, on the type of medical care unit and on clinical experience and surgical skill of the attending physician, in addition to the risk implicit in the surgical procedure itself. All these will be predisposing factors to treatment success or failure; nevertheless, the opinion or perception of the patient regarding the feeling of well-being he/she can experience and that represents the sum of subjective and personal sensations about "feeling good" should be assessed in order to determine the impact of therapeutic interventions. User satisfaction and health-related quality of life should become indicators of countries' health systems performance, and have to be inherent to all medical specialties. Self-perceived health is independently associated with clinical diagnosis and allows predicting the use of health services. If health care outcomes are not measured from the perspective of patients, the evaluation of interventions can be considered incomplete, since it is the intervened subjects who should express their opinion on the way their lives or their health are affected. For this, we resort to already validated instruments that measure quality of life after a healthcare intervention. There are generic instruments whose purpose is to measure quality of life changes at different moments of disease. The determination of utility or preferences individuals assign to the different health states of the instrument provides a single score that numerically reflects the quality of life (Euroqol 5-D and International Prostate Symptom Score [IPSS]) ${ }^{3}$.

Therefore, the purpose of this work was to determine the quality of life associated with the surgical technique in patients after being operated on with urethral plasty, in an effort to more accurately know the consequences of disease and its treatment, and especially to know how patients perceive themselves after treatment, regardless of their physical conditions and of their treating physician's concept of successful treatment.

\section{Method}

After authorization by the Local Research and Ethics in Health Research Committee of the Mérida No. 3203 High-Specialty Medical Unit (UMAE - Unidad Médica de Alta Especialidad), with registration number R-2016-3203-7, an observational study was carried out to determine the quality of life in patients undergoing urethral plasty between January 2011 and December 2015. Patients with lower urinary symptoms unrelated to urethral stricture were excluded.

The Euroqol 5-D and IPSS questionnaires were applied after the plasty to measure the quality of life. The degree of well-being and satisfaction was measured by the perception of the patient associated with plasty-inherent morbidity, characterized by recurrence of the stricture.

IPSS eighth item assessed the impact of lower urinary tract symptoms after the plasty as the degree of satisfaction according to patient perception. With the Euroqol 5-D, five health dimensions were assessed: mobility, self-care, usual activities, pain/discomfort and anxiety/depression; pain was assessed by means of a visual analogue scale.

All the information was concentrated in a data matrix that only members of the research group had access to. The information was analyzed with the statistical program SPSS v. 20.0. Descriptive statistics were performed. Chi-square and Pearson's tests were used. The degree of association of prognostic factors with quality of life was estimated with logistic regression and linear regression analyses. Accumulated incidence, relative risk with its $95 \%$ confidence interval (Cl) and the fraction of recurrence attributable to exposure were calculated. A Kaplan-Meier curve was plotted to analyze disease recurrence-free interval.

\section{Results}

Twenty-nine urethral plasty-operated patients were studied. Average age was $60.72 \pm 16.4$ years at the time of surgical reconstruction. Mean body mass index was $27.99 \pm 3.92 \mathrm{~kg} / \mathrm{m}^{2}$. Type 2 diabetes mellitus was found in $27.6 \%$ of cases, and systemic arterial hypertension in $44.8 \%$. Of all the cases, $34.5 \%$ referred smoking.

An iatrogenic cause was present in $58.6 \%$ of patients, followed by traumatic cause in $24.1 \%$, idiopathic in 
$13.8 \%$ and inflammatory in $4 \%$. Mean length of the urethral lesion was $3.12 \pm 2.685 \mathrm{~cm}$; lesion length mode was $1 \mathrm{~cm}$ in $27.6 \%$ of patients $(p=0.44$; value obtained with contingency tables, for patients treated with excision and anastomosis).

Bulbar urethra was affected in $41.37 \%$ of patients, followed by the penile urethra in $20.6 \% ; 37.93 \%$ of patients had more than one urethral segment compromised ( $p=0.046$; value obtained with contingency tables for the entire group). Of the 29 patients, $20.7 \%$ received multiple urethral dilatations prior to the plasty. Internal urethrotomy under direct vision was the procedure in $55.2 \%$, out of whom $24.1 \%$ underwent the procedure on one occasion, $13.8 \%$ on two, $3.4 \%$ on three, $3.4 \%$ on four and $6.9 \%$ on five occasions; one patient had underwent 18 previous internal urethrotomies.

Regarding the surgical technique employed, $55.2 \%$ underwent oral mucosa grafting, and $34.5 \%$ were treated with excision and anastomosis. Three more patients were treated with different techniques: one was operated on with the Wolfe technique or retroauricular skin graft, with relapse at 12 months, and two were treated with more than one surgical technique and relapsed at 3 and 43 months.

With the logistic regression analysis, relapse occurred in $69 \%$ of patients ( $p=0.047$; value obtained by multivariate logistic regression analysis), and overall prediction certainty of the model was $89.7 \%$ ( $p=0.031$; value obtained by multivariate logistic regression analysis). Patient distribution by etiology and by lesion length in those who relapsed was different according to the type of plasty (Table 1).

As for the presence and severity of lower urinary symptoms according to IPSS, the distribution according to the surgical technique is observed in figure 1. Patient perception of quality of life after the plasty according to the answer to IPSS item 8 is shown in figure 2. The distribution of health status according to the Euroqol health status self-assessment thermometer is presented in figure 3 . Patient perception of pain severity is depicted in figure 4 .

Cumulative incidence of relapse in the entire the group was $68 \%$. Relative risk for experiencing a relapse was 2.19 (95\% Cl: 1.69-2.8). The fraction attributable to exposure was $54 \%$. The data about the relapse-free interval are shown in table 1. Absolute risk of relapse for patients who were operated with oral mucosal graft was $75 \%$ (95\% Cl: 54-96). Absolute risk of relapse for the excision and anastomosis technique was $62 \%(95 \% \mathrm{Cl}$ : $35-88)$. Relapse-free interval according to the type of plasty is shown in figure 5 .
Table 1. Percentage of patient relapse by etiology, lesion length and type of plasty

\begin{tabular}{|c|c|c|c|}
\hline \multirow[t]{2}{*}{ Type of plasty } & \multirow{2}{*}{$\begin{array}{l}\text { Lesion } \\
\text { etiology }\end{array}$} & \multicolumn{2}{|c|}{ relapse* } \\
\hline & & No & Yes \\
\hline \multirow{3}{*}{$\begin{array}{l}\text { Excision and primary } \\
\text { anastomosis }\end{array}$} & Idiopathic & 100 & 0 \\
\hline & latrogenic & 20 & 80 \\
\hline & Traumatic & 75 & 25 \\
\hline \multirow[t]{4}{*}{ Oral mucosa graft } & Idiopathic & 0 & 100 \\
\hline & latrogenic & 27.3 & 72.7 \\
\hline & Traumatic & 50 & 50 \\
\hline & Inflammatory & 0 & 100 \\
\hline Wolfe or retroauricular skin graft & Idiopathic & 0 & 100 \\
\hline \multirow{2}{*}{$\begin{array}{l}\text { More than one surgical } \\
\text { technique }\end{array}$} & latrogenic & 0 & 100 \\
\hline & Traumatic & 0 & 100 \\
\hline \multicolumn{4}{|l|}{ Lesion length (cm) } \\
\hline \multirow{3}{*}{$\begin{array}{l}\text { Excision and primary } \\
\text { anastomosis }\end{array}$} & 1 & 66.7 & 33.3 \\
\hline & 2 & 0 & 100 \\
\hline & 2 & 100 & 0 \\
\hline \multirow[t]{7}{*}{ Oral mucosa graft } & 1 & 0 & 100 \\
\hline & 2 & 0 & 100 \\
\hline & 3 & 0 & 100 \\
\hline & 3 & 40 & 60 \\
\hline & 4 & 50 & 50 \\
\hline & 6 & 0 & 100 \\
\hline & 10 & 0 & 100 \\
\hline Wolfe or retroauricular skin graft & 2 & 0 & 100 \\
\hline \multirow{4}{*}{$\begin{array}{l}\text { More than one surgical } \\
\text { technique }\end{array}$} & 1 & 0 & 100 \\
\hline & 10 & 0 & 100 \\
\hline & Median & \multicolumn{2}{|c|}{$\begin{array}{l}95 \% \text { confidence } \\
\text { interval }\end{array}$} \\
\hline & & $\begin{array}{l}\text { Lower } \\
\text { limit }\end{array}$ & $\begin{array}{l}\text { Upper } \\
\text { limit }\end{array}$ \\
\hline $\begin{array}{l}\text { Excision and primary } \\
\text { anastomosis }\end{array}$ & 12 & 8.494 & 15.506 \\
\hline Oral mucosa graft & 6 & 3.992 & 8.008 \\
\hline Wolfe or retroauricular skin graft & 12 & - & - \\
\hline $\begin{array}{l}\text { More than one surgical } \\
\text { technique }\end{array}$ & 3 & - & - \\
\hline
\end{tabular}




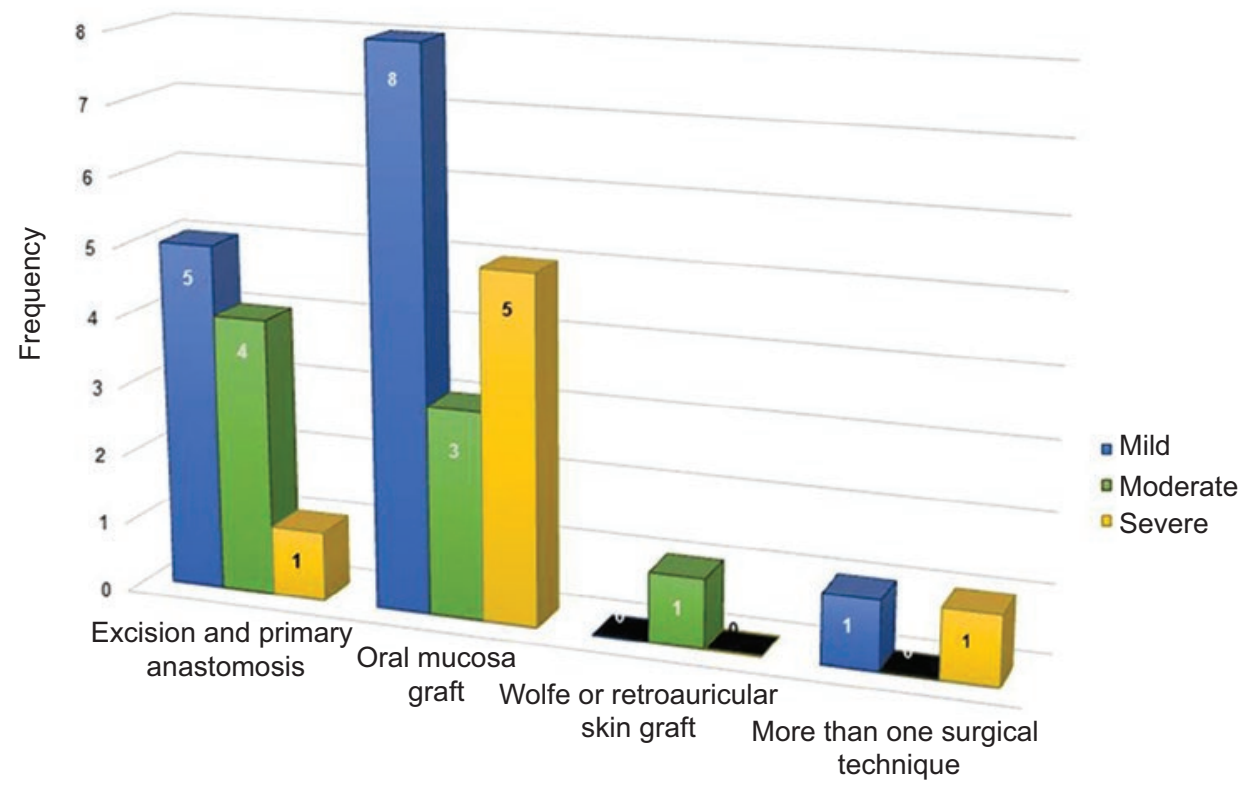

Figure 1. According to the classification of urinary symptoms severity, the majority of patients operated with the oral mucosa graft technique experienced mild urinary symptoms, followed by serious symptoms. More than $50 \%$ of the study patients were in this group.

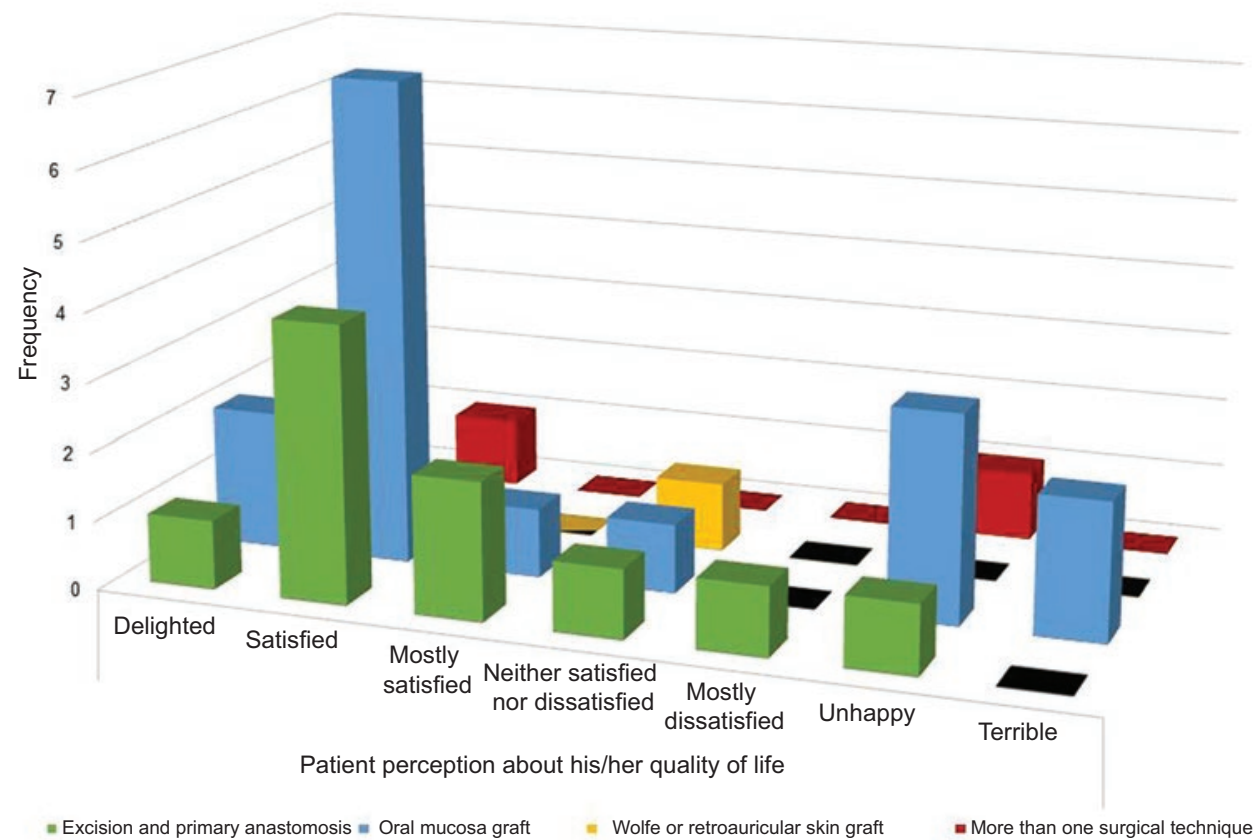

Figure 2. In general, according to the answer collected by IPSS eighth item, patients referred being satisfied with their quality of life; some referred being mostly satisfied and others perceived it as excellent. Two of the three patients in whom more than one surgical technique was used answered satisfied and excellent. This highlights the importance of taking into account patients' opinion, regardless of the success of the surgical technique as assessed by cystoscopy or any other diagnostic method.

\section{Discussion}

Treatment of urethral stricture will depend on the cause and mechanism of the lesion, as well as on length of the defect, knowledge and experience of the treating physician to consider the most appropriate therapeutic option, as well as his/her surgical skills for a successful repair. However, patient perception about his/her health or disease conditions after a therapeutic intervention is important to determine his/her degree of well-being and satisfaction. Taking into account the specific factors that may have influenced on whether or not an improvement in quality of life was achieved, makes it possible to support aspects such 


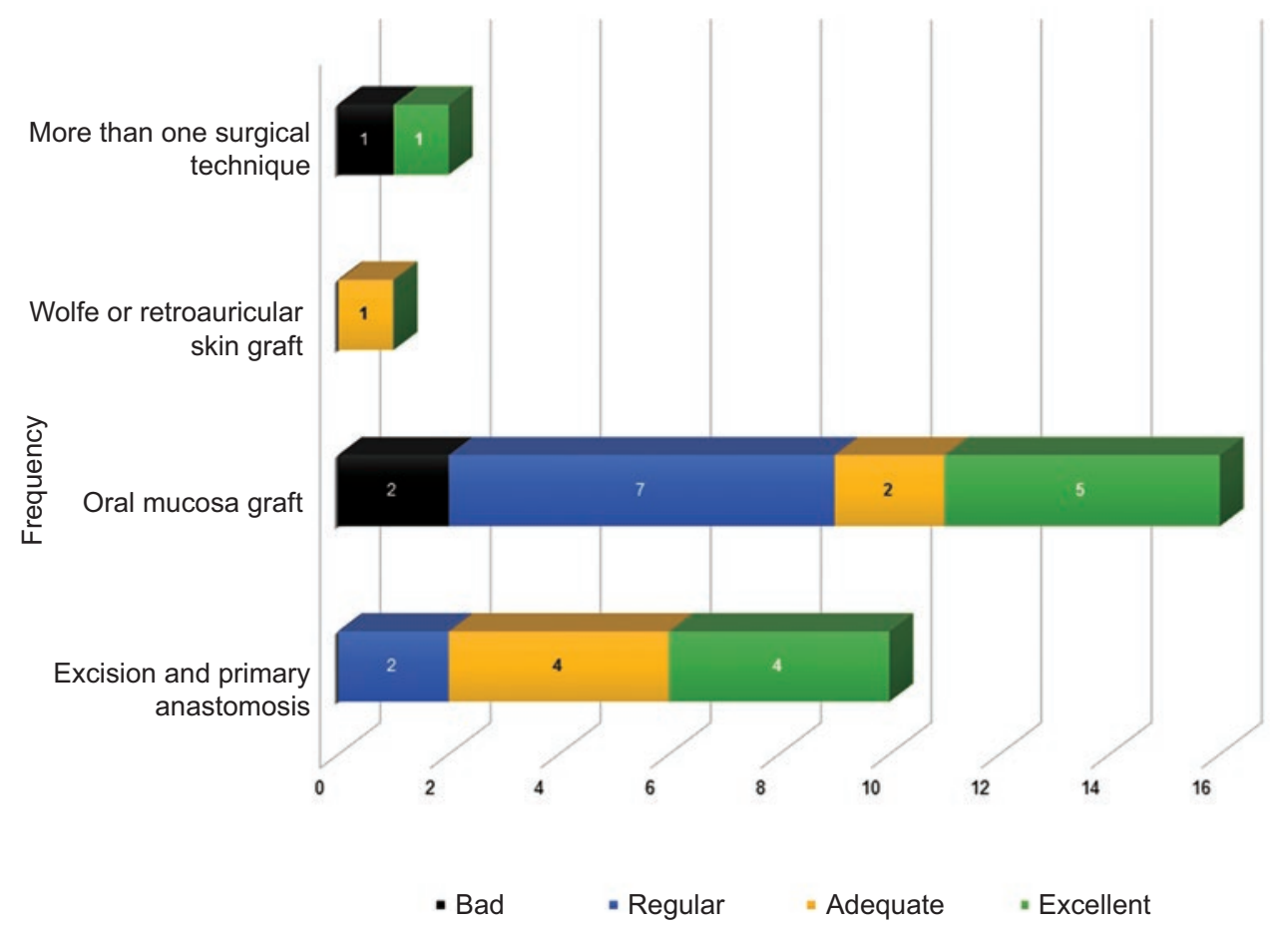

Figure 3. Patients' health status, as detected by the EuroQol Health Status Self-Assessment Thermometer, was regular in most subjects operated on with the oral mucosa graft technique. However, patients operated on with excision and anastomosis referred an adequate or excellent health status. Despite the difference of subjects in each group, this allows visualizing that, according to the surgical technique, the patient feels better with excision and anastomosis, which can be a point of reference for future works where both techniques can be compared.

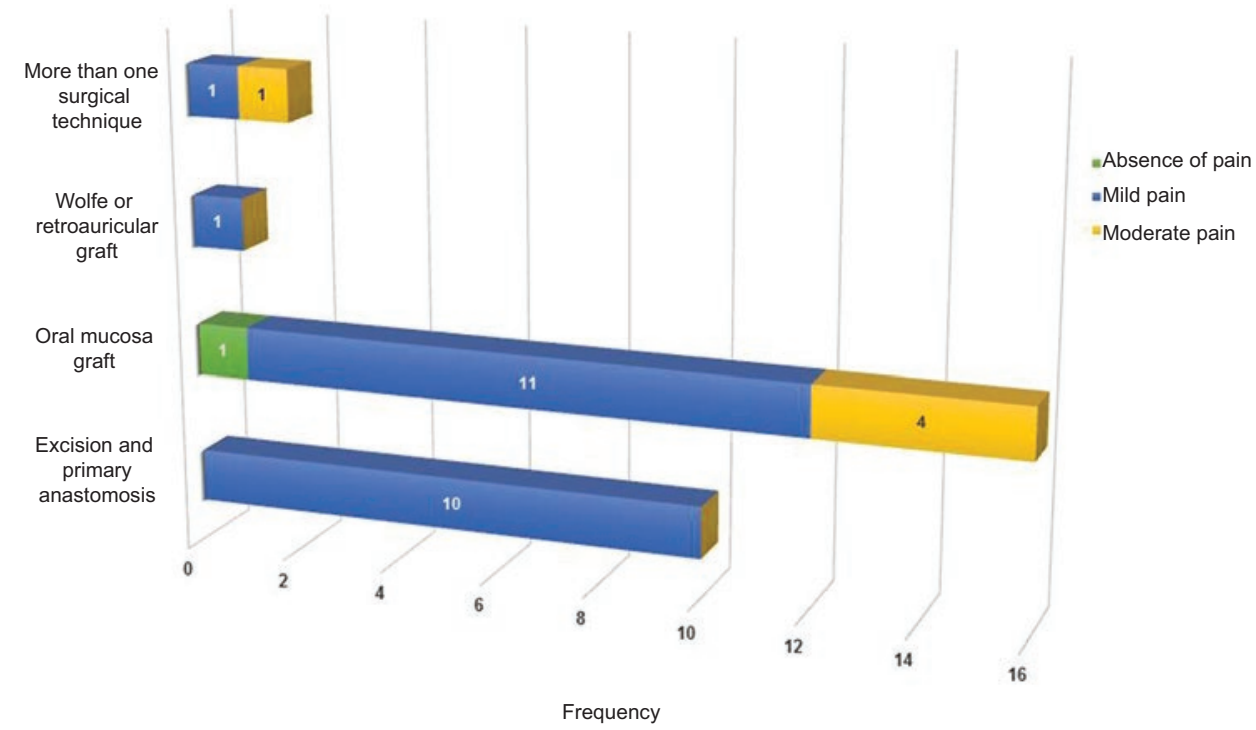

Figure 4. Pain measurement by the visual analogue scale clearly showed that patients with graft may have post-plasty pain. The technique with excision and anastomosis produced minimal painful sensation in this group of patients. These data can be a guideline for future studies or to regulate management protocols for patients with urethral stricture.

as the presence of any complication or disability, or else economic problems related to disease itself ${ }^{3}$. Urological treatments become increasingly frequent as the patient ages. Urethral instrumentation predisposes to injuries that will require treatment later, and whose presentation form will be determined by the characteristics of the study population, as well as by the knowledge and clinical experience of the treating physician.

The prognosis of patients treated for stenosis should generate academic interest among specialists and medical units, and lead to fundamental questions 


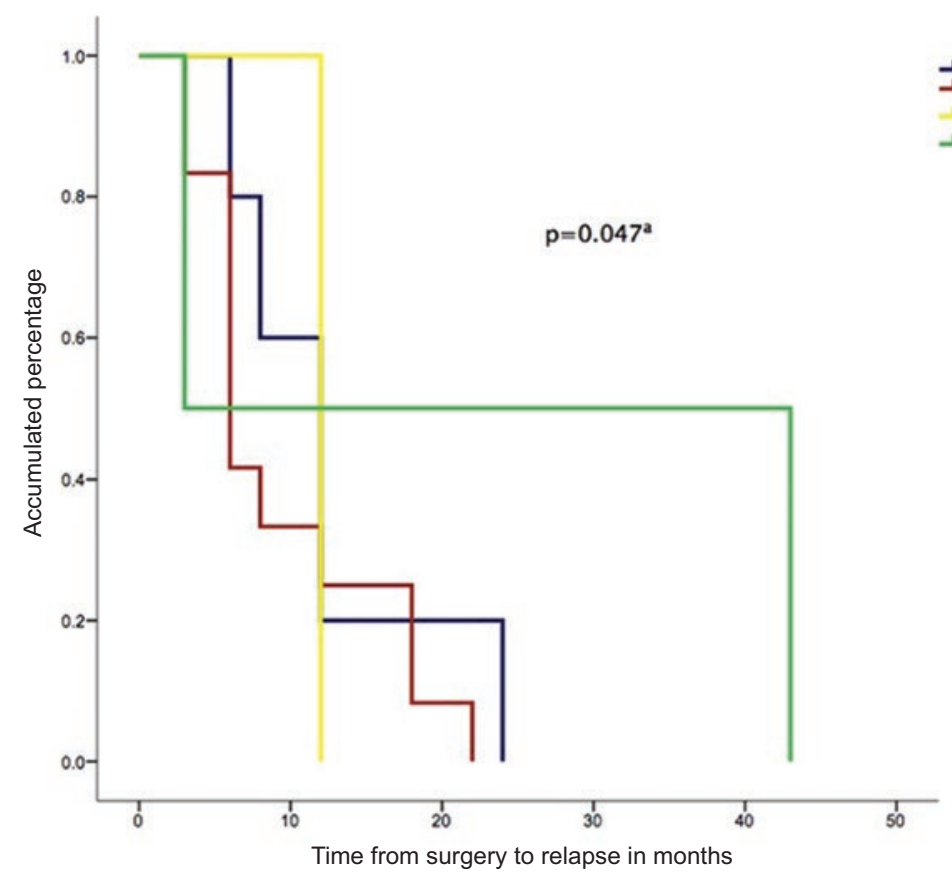

Type of plasty

Excision and primary anastomosis

cosa graft

We or retroauricular skin graft

More than one surgical technique

Figure 5. Relapse-free interval with each type of surgical intervention was variable; however, most subjects experienced relapse at between 6 and 12 months. Despite the relapse-free interval variability, the two most common surgical techniques had 100\% of relapses at between 20 and 25 months. Although two patients required plasty with more than one surgical technique, the relapse was late and occurred up to 43 months after the operation. The regression analysis showed an important statistical significance, which complemented the findings shown by the Kaplan-Meier analysis.

about the medical care process, among which the most basic is: "What is surgical success?" Traditionally, the academic definition of a successful urethroplasty is the lack of need for a secondary procedure. Mild urethral lumen asymptomatic narrowness has been shown to occur in up to $35 \%$ of recurrent strictures. According to Erickson and Ghareeb ${ }^{4}$, surgical success after an urethroplasty is related to the anatomical complexity of the reconstructive technique. Bertrand et al. ${ }^{5}$ reported that men with recurrent cystoscopy are more likely to be dissatisfied (odds ratio: 4.96; 95\% Cl: 2.07-11.90) and have significantly worse uroflowmetry measurements; $89.38 \%$ of the patients they studied referred being satisfied or very satisfied after being operated on with anterior plasty, and those who reported few lower urinary symptoms and less pain according to the IPSS referred higher satisfaction.

Another associated question should address how to define surgical success, i.e., "What is the best way to monitor the patient after urethroplasty?". Most patients only care about their ability to empty the bladder. The ideal follow-up strategy should be able to account for both the surgeon and the patients: it has to consider the capability of the surgeon to define success or failure and protect patients' genitourinary health without subjecting them to unnecessary procedures. According to the study by Liu et al. ${ }^{6}$, half the relapses occur within one year, with most of them doing it within the first 6 months. In the patients operated at UMAE Mérida, relapse was found to occur at a $69 \%$ rate, with an average of 8 months to take place. Patients with short urethral lesions experienced less relapses and had a perception of a better health status. Duration and intensity of surveillance after urethroplasty should be individualized. It is important being able to define those patients at high risk of recurrence and in what period of time, based on the characteristics of the patient, the disease and the reconstructive technique, thus allowing the design of individualized follow-up protocols 6 . Using validated strategies to measure clinical outcomes, assessing urinary symptoms before and after surgery, and being able to detect recurrence seems reasonable, since most patients are expected to develop new or persistent micturition symptoms ${ }^{4}$. The application of the Euroqol-5D and IPSS questionnaires allowed us finding a relapse in more than half the cases. With these instruments, the degree of well-being and satisfaction was measured based on patient perception associated with plasty-inherent morbidity, characterized by the recurrence of strictures. With the IPSS, recurrence was determined by the presence of lower urinary tract symptoms (urinary flow intermittency, effort to start 
urination or tenesmus, weak flow, urinary frequency, nocturia, urgency, feeling of incomplete voiding) and the quality of life. Most patients referred feeling between quite satisfied and delighted. However, Tam et al. ${ }^{7}$ carried out a study to validate the IPSS and reported that the area under the ROC curve for the question about quality of life was 0.66 , and that total value for the instrument was 0.56 . There are differences with our patients that should be considered, and the information should be handled with caution. The answer to the question about quality of life depends on patient perception. The subjects studied by Tam et al. ${ }^{7}$ were on average 45 years old, younger than ours, and the concept of satisfaction can therefore be different. In that study, the IPSS comparison was made against cystoscopy, and the way this invasive procedure allows measuring the quality of life of a patient with or without stenosis relapse is not referred; surgical repair integrity was assessed at 3, 6 and 12 months. The patients we studied were followed-up for up to 43 months after the intervention, and most cases that relapsed did it during the first year after the plasty. While it is true that cystoscopy allows visualizing surgical procedure success in terms of physical evidence of its integrity, it does not explain patient perception of his/her health status. Clinical instruments such as questionnaires, where the scores depend on patient subjective answer, should be compared with similar instruments, since there is the risk for underestimating a tool that can be useful. For this, we must be clear about the scope of our interventions and about what do we expect from them in order to determine how they are going to be assessed. Patient satisfaction after urethral plasty is not only due to a decrease in urinary discomfort, but also to the absence of pain. Given the importance, although often conflicting, of both anatomical findings and those reported by the patient for success after urethroplasty to be determined, both parameters should be simultaneously assessed, but separately reported for all interventions. This should facilitate the comparison of surgical results between different surgeries, different surgeons and various types of strictures ${ }^{4}$.

In addition to the assessment of relapse after surgery and how the patient perceives his/her health status, it is necessary to inquire about the impact the intervention has on patient's life. For this, there is another validated generic instrument, the Euroqol 5-D, which evaluates five health dimensions: mobility, selfcare, usual activities, pain/discomfort and anxiety/depression $^{8}$. Jackson et al ${ }^{9}$ used this instrument to assess urethral reconstruction from the patient's perspective. They found that $33 \%$ of patients were satisfied and $54 \%$ very satisfied. Our patients operated on with oral mucosa graft referred, mostly, a regular health status (43.75\%), while $31.25 \%$ reported an excellent health status, showing that one technique has better results than the other. In contrast, the predominant health statuses with the excision and anastomosis technique were adequate and excellent. However, these are data that should be taken with caution, since the number of subjects operated on with each technique was different (16 and 10, respectively). Furthermore, we found a significant association between the length of the lesion and the perception the patient has of his/her health status through the EuroQol-5D. Although the purpose of the instruments used is to measure the quality of life, they differ in their items. Notwithstanding, we found that the presence of IPSS-detected lower urinary symptoms had a significant association with patient perception about his/her health status in the EuroQol-5D ( $p=0.004)$; the more the symptoms referred by patients, the greater the deterioration of the perception of their health status. Furthermore, the individual perception each patient has about his/her health status as assessed with IPSS eighth question was significantly related to quality of life as assessed with EuroQol-5D ( $p=0.003)$. These data allow considering that, at least for this study population, the information collected by either instrument guides us about the perception the patient has of his/ her clinical status. The performance of urethroplasty is a worthwhile intervention from the patients' perspective. The use of validated instruments to measure quality of life can serve as a point of reference by means of which surgeons and medical institutions can compare their performance ${ }^{9}$. The information they provide allows to identify different morbidity and well-being states, and assess the impact of therapeutic and healthcare interventions on individuals.

\section{Conclusions}

The probability of relapsing after plasty is 2.19 -fold higher. Accumulated incidence was $68 \%$ and the fraction attributable to exposure to the surgical procedure was $54 \%$. It is necessary to generate databases that allow observing the behavior of the phenomenon over time and in the treated population, and they should include the measurement of how the patient perceives him/herself and his/her situation.

There are limitations to the study that should be acknowledged. The sample size, despite representing 
the universe of our hospital patients, is not enough to allow a detailed analysis of different subgroups. The majority of patients have a limited sociocultural level, which makes the reading, understanding and filling of the questionnaire difficult. Notwithstanding, it is important to emphasize that it is an advantage that the same surgeon operated on all study patients, which decreases variations in surgical techniques, but at the same time it also represents a constraint for comparing different medical criteria. Despite its limitations, the study is one of the few conducted in Mexico evaluating quality of life according to the reconstructive surgery chosen.

Urethral stricture treatment success should be integrated with the perception the patient has of his/her quality of life and health status, in addition to the surgical technique used and patient conditions.

\section{Funding}

This work has not received any funding.

\section{Conflicts of interest}

The authors declare not having any conflicts of interest.

\section{References}

1. Jordan G, Chapple C, Heyns C. An international consultation on urethral strictures. Marrakech, Morocco; 2012. Disponible en: www.siu-urology.org.

2. Alwaal A, Blaschko SD, McAninch JW, Breyer BN. Epidemiology of urethral strictures. Transl Androl Urol. 2014;3:209-13.

3. Moreno Altamirano L. Epidemiología clínica. 3. ${ }^{\text {a }}$ ed. Ciudad de México: McGraw-Hill; 2013. 329 p.

4. Erickson BA, Ghareeb GM. Definition of successful treatment and optimal follow-up after urethral reconstruction for urethral stricture disease. Urol Clin North Am. 2017;44:1-9.

5. Bertrand LA, Voelzke BB, Elliott SP, Myers JB, Breyer BN, Vanni AJ, et al. Measuring and predicting patient dissatisfaction after anterior urethroplasty using patient reported outcomes measures. J Urol. 2016;196:453-61.

6. Liu JS, Dong C, González CM. Risk factors and timing of early stricture recurrence after urethroplasty. Urology. 2016;95:202-7.

7. Tam CA, Elliott SP, Voelzke BB, Myers JB, Vanni AJ, Breyer BN, et al. The International Prostate Symptom Score (IPSS) is an inadequate tool to screen for urethral stricture recurrence after anterior urethroplasty. Urology. 2016;95:197-201.

8. Dolan P. Modeling valuations for EuroQol health states. Med Care. 1997;35:1095-108.

9. Jackson MJ, Chaudhury I, Mangera A, Brett A, Watkin N, Chapple CR, et al. A prospective patient-centred evaluation of urethroplasty for anterior urethral stricture using a validated patient-reported outcome measure. Eur Urol. 2013;64:777-82. 